Accepted at the Journal of Social and Personal Relationships

\title{
SuPPort in ReSPonse to a SPOUSE's Distress: Comparing Women AND Men In SAME-SEX AND DIFFERENT-SEX MARRIAGES
}

(Running head: Support in Response to a Spouse's Distress)

\author{
Mieke Beth Thomeer ${ }^{1}$ \\ Amanda Pollitt ${ }^{2}$ \\ Debra Umberson ${ }^{3,4}$
}

${ }^{1}$ Department of Sociology, The University of Alabama at Birmingham, Heritage Hall 460, 1401

University Blvd., Birmingham, AL 35233. mthomeer@uab.edu

${ }^{2}$ Department of Health Sciences, Northern Arizona University

${ }^{3}$ Department of Sociology, University of Texas at Austin

${ }^{4}$ Population Research Center, University of Texas at Austin

Acknowledgement: This research was supported by grants R21AG044585 (PI: Umberson) and P30AG066614 (awarded to the Center on Aging and Population Sciences at The University of Texas at Austin) from the National Institute on Aging and grants P2CHD042849 (Population Research Center,) and T32HD007081 (Training Program in Population Studies), awarded to the Population Research Center at The University of Texas at Austin by the Eunice Kennedy Shriver National Institute of Child Health and Human Development. This study was also funded in part by the National Institute on Alcohol Abuse and Alcoholism grant number F32AA025814 (PI: Pollitt). The content is solely the responsibility of the authors and does not necessarily represent the official views of the National Institutes of Health. 


\begin{abstract}
Support for a spouse with psychological distress can be expressed in many different ways. Previous research indicates that support expression is shaped by gender, but we do not know much about how support within marriage is provided in response to a spouse's distress outside of a different-sex couple context. In this study, we analyze dyadic data from 378 midlife married couples (35-65 years; $N=756$ individuals) within the U.S. to examine how men and women in same- and different-sex relationships provide support when they perceive that their spouse is experiencing distress. We find women in different-sex couples are less likely to report taking care of their distressed spouse's tasks or giving their distressed spouse more personal time and space compared to women in same-sex couples and men. We also find that men in different-sex couples are less likely to report encouraging their spouse to talk compared to men in same-sex couples and women. Being personally stressed by a spouse's distress is positively associated with providing support to that spouse, whereas feeling that a spouse's distress is stressful for the marriage is negatively associated with providing support. This study advances understanding of gendered provisions of support in response to psychological distress in marriage, moving beyond a framing of women as fundamentally more supportive than men to a consideration of how these dynamics may be different or similar in same- and different-sex marital contexts.
\end{abstract}

Keywords: distress, dyadic data analysis, gay/lesbian relationships, gender, gender differences, marriage, mental health, social support, stress 
Within a marriage, the psychological distress of one spouse impacts relationship dynamics (Meyer et al., 2019). As outlined in dyadic perspectives, there is an interplay between the distress of one spouse and how the other spouse reacts, including how spouses express support for each other (Bodenmann, 1997). We define support as feeling cared and provided for, assisted, and loved (Thoits, 2011) and recognize support provisions as a a central and critical dynamic within marriages (Ogolsky et al., 2017). We focus specifically on how people provide support when they perceive that their spouse is distressed. Previous research indicates that whether and how support is expressed within marriage depends on gender, but most of this research is based on different-sex couples (Swinkels et al., 2019; Taylor, 2015; Thomeer \& Ostergren Clark, 2021). How a person expresses support when they perceive that their spouse is experiencing psychological distress likely depends on their own gender, the gender of their spouse, and whether in a same-sex or different-sex relationship.

Additionally, stress is relational, such that one spouse's distress crosses (or "spills") over to impact the other spouse (i.e., personal stress level) and the general well-being of the marriage (i.e., marital stress level; Bodenmann, 1997). The extent to which a spouse's distress is viewed by the other spouse as personally or maritally stressful likely shapes whether and how support is expressed. Further, given that within different-sex couples, women's distress is more impactful for men's stress levels than vice versa (Thomeer et al., 2013), we expect that gender-one's own gender, the spouse's gender, and the interaction between two-will moderate the extent to which personal and marital stress levels matter for support expressions.

In this study, we address four primary research questions, focusing on the period in which respondents believed their spouse experienced their highest level of psychological distress over the course of the marriage. First, how do people within midlife marriages provide support when 
they perceive that their spouse is distressed? Second, how does this support vary depending on their own gender, their spouse's gender, and whether they are in a same-sex or different-sex couple? Third, does this support depend on the extent to which the spouse's distress is perceived to be personally stressful or maritally stressful? And fourth, do these personal and marital stress level associations with support provisions vary by one's own gender, spouse's gender, and whether in a same-sex or different-sex couple? We answer these questions with an analysis of dyadic data from a survey of 378 midlife married couples $(N=756$ individuals): 157 female same-sex couples, 106 male same-sex couples, and 115 different-sex couples. We focus on midlife couples, defined as spouses aged 35 to 65 years, given that this is a time in which health and relationship patterns for later life are established and maintained (Thomeer \& Ostergren Clark, 2021). Yet in focusing on midlife couples - and specifically a majority White and majority college-educated sample — we recognize the privilege experienced by our respondents (Allen \& Mendez, 2018). This privilege is shaped by the racial and class composition of the sample, as well as by the general benefits offered by a societal context that advantages the married through policies and other institutional structures, likely shaping how people experience distress and how they provide and receive support (Berger \& Carlson, 2020).

\section{Expressions of Support in Response to Psychological Distress}

Building on dyadic frameworks of support, we examine how support is expressed within marriage when one spouse is experiencing high levels of psychological distress (Bodenmann, 1997). Support is a key relationship maintenance strategy, helping to preserve relationships during strained periods — including periods of psychological distress for a spouse — and contributing to relationship satisfaction (Randall \& Messerschmitt-Coen, 2019). Marriages with high levels of relationship quality are characterized by higher levels of support exchange, while 
an absence of support characterizes relationships with low or ambivalent relationship quality (Proulx, Ermer, \& Kanter, 2017). Qualitative studies examining support in response to a spouse's distress demonstrate that support is expressed in multiple ways, including through doing tasks for the other person, giving the other person time and space to process their feelings, talking to the other person, and providing a new perspective on a person's problems (Reczek et al., 2020; Thomeer et al., 2013; Umberson et al., 2017).

\section{Gender within Different-Sex and Same-Sex Marital Contexts}

Support within a marriage — including whether, how, and when that support is provided in cases of a spouse's psychological distress—are likely shaped by a person's own gender identity as well as their spouse's gender (Thomeer et al., 2020). This is because gender is formed and maintained through social interaction with others, including within romantic relationships (West \& Zimmerman, 1987). Dyadic understandings of gender within marriage draws attention to the fact that not all marriages are composed of different-sex partners, despite the assumptions of many past studies (Fish \& Russell, 2018). These studies of different-sex couples suggest that men generally provide less support than women, and women tend to be more intensive in the support they provide (e.g., engaging in more multitasking, more inflexible tasks; Neff \& Karney, 2005; Swinkels et al., 2019). These gender dynamics within different-sex couples are theorized to be driven by broader gender discourses regarding masculinity and femininity (e.g., men as providers and women as nurturers) and structural constraints (e.g., women being paid less in the formal workforce so they specialize in care work at home) as explaining gendered patterns of support (Homan, 2019; Taylor, 2015).

One key gender discourse, especially consequential for White, college-educated, cisgender, heterosexual, married people, is hegemonic masculinity, defined as the dominant 
culture's ideals of manhood, emphasizing strength, stoicism, and self-reliance (Connell \& Messerschmidt, 2005). According to this discourse, within different-sex relationships, men tend to be less attuned than women to their spouse's emotional and psychological needs because gendered scripts related to hegemonic masculinity construct men as emotionally unavailable (Thomeer et al., 2013). This masculinity dynamic potentially makes them view themselves as illsuited to provide support when their wife is distressed. In contrast, discourses of emphasized femininity include the expectation that women should accommodate to men's interests and desires in ways that are opposite but understood as complementary to hegemonic masculinity (Connell \& Messerschmidt, 2005). Thus, women within different-sex relationships are often constructed as "emotional experts," seen as responsible for supporting their husband and his emotions (Simon \& Nath, 2004).

Dyadic understandings of gender within marriage critique too much emphasis on different-sex couples, instead highlighting that the marital dynamics of men and women are diverse, both across and within couples (Thomeer et al., 2020). This diversity reflects the complexities of gender as a social construction formed within social interactions and institutions (Risman, 2004). Including same-sex and different-sex couple samples within a study of support dynamics in response to distress is an important step in developing a gendered and dyadic understanding of support within marriage. Building on past research on gendered dynamics within same-sex couples, we propose two possibilities for how gender might operate to shape support provisions within same-sex married contexts, with the second possibility more supported by previous research. Prior studies of different-sex couples that emphasize gender difference (Neff \& Karney, 2005; Swinkels et al., 2019; Taylor, 2015) lead us to expect large differences between women and men in same-sex relationships, with two men expressing support for each 
other differently than two women. In this way, heteronormative gender constructions that influence support in response to psychological distress would be produced and reproduced within same-sex couples, especially in a relatively advantaged same-sex couple population (e.g., majority White, majority college-educated, cisgender; Few-Demo, 2015), and we would expect support dynamics in male same-sex couples to be informed by traditional masculinity discourses and dynamics in female same-sex couples to be informed by traditional femininity discourses.

Alternatively, because gender scripts are highly dependent on social and relational contexts (Goldberg \& Smith, 2013; Reczek et al., 2020), it may be that social constructions of gender within same-sex couples are distinct from those for different-sex couples. Although men and women in same-sex relationships may be strongly influenced by traditional masculinity and femininity discourses (especially if they occupy relatively privileged social statuses as is the case in our sample; e.g., White, college-educated, middle-class, married; Allen \& Mendez, 2018), they are more likely to subscribe to gender scripts that de-emphasize power differences between partners, often translating into more equality within same-sex compared to different-sex relationships (Goldberg \& Smith, 2013; Prickett et al., 2015). For example, a qualitative study of same-sex couples providing support for spouses with psychological distress found that most respondents discussed how the non-distressed partner supported the distressed partner, with this pattern similar across both same-sex male and same-sex female couples (Thomeer et al., 2015). Based on this prior research, we would expect spousal differences in support expressions when comparing men and women in different-sex couples but more similarity in support expressions for men and women in same-sex relationships. 


\section{Perceived Impact of Spouse's Distress}

We further expect that how support is expressed depends on the perceived impact of the spouse's distress both for the respondent personally (i.e., personal stress level) and their marriage (i.e., marital stress level). As emphasized in a dyadic coping perspective (Bodenmann, 1997), people have profound influences on each other and live their lives in tandem as they age; therefore, understanding any person's experiences requires looking to the people around them, perhaps especially their spouse. Stress, in particular, has been shown to cross over within intimate relationships, as illustrated in previous studies showing that the psychological distress of one partner is associated with both increased stress for the other partner and increased strain and conflict within the relationship (Meyer et al., 2019; Thomeer et al. 2013). People who feel more negatively impacted by their partner's distress - either in terms of their personal or marital stress levels - may have less motivation or energy to provide this support. Alternatively, to the extent that providing support might be successful in reducing a partner's distress, this support could serve to indirectly improve the well-being of the spouse and strengthen the relationship.

The links between perceived stress levels and support may further depend on whether that impact is personal or marital/relational, although this has not been previously examined. Previous studies and theoretical frameworks suggest that women are more reactive to marital stress than men, reflecting constructions of women as more emotional than men and unequal divisions of labor wherein women are more responsible for and attentive to the well-being of intimate partners than are men (Simon \& Nath, 2004; Taylor, 2015). Although this has been primarily studied in different-sex couples, there is emerging evidence of differences between men and women in reactivity to stressors in same-sex couples as well (Umberson et al., 2020). 


\section{Present Study}

In our first two research questions, we ask: How do people provide support when they perceive that their spouse is distressed? and How does this support vary depending on their own gender, their spouse's gender, and whether they are in a same-sex or different-sex couple? We expect that most respondents will provide support, but that men married to women will provide less support than other groups. We further expect that there will be gender differences in how that support is expressed. In our third and fourth research questions, we ask: Does this support depend on the extent to which the spouse's distress is perceived to be personally or maritally stressful for the respondent? and, Do these associations vary by own gender, spouse's gender, and whether in a same-sex or different-sex couple? We expect that support will depend on how stressful respondents perceive their spouse's distress is for their own stress levels and for the marriage. We also expect that women's support provisions - regardless of whether married to a man or a woman — will be more impacted by perceived personal and marital stress levels than men's.

\section{Method}

\section{Study Procedure}

After receiving IRB approval for the study design from the University of Texas at Austin, study participants were recruited systemically through Massachusetts's vital records office and snowball sampling. Massachusetts was chosen because it was the first state to legalize same-sex marriage (in 2004) and has a sizeable population of long-term same-sex married couples. Samesex couples between the ages of 35 and 65 and married between 2004 and 2012 were identified using the Massachusetts Registry of Vital Records and sent invitations to participate. Those who participated were also asked to refer same- and different-sex couples of a similar age within their 
social networks with the goal of creating comparable groups of same- and different-sex couples on total relationship duration, age, and place of residence. Additionally, we sent recruitment letters to different-sex couples from zip codes corresponding to the neighborhoods of enlisted same-sex couple study participants identified using publicly available city lists in Massachusetts that included demographic data on household members. Some of the couples that were married in Massachusetts lived in other states at the time they participated; in addition, participants referred couples that resided in states other than Massachusetts. Both spouses separately completed an online survey on a range of questions about relationships and health, with a focus on how spouses in long-term relationships influenced each other. Each spouse was paid \$50 for participating. Data are publicly available at the Inter-University Consortium for Political and Social Research (https://doi.org/10.3886/ICPSR37404.v1).

\section{Participants}

In the final sample, 55 percent of male same-sex couples, 62 percent of female same-sex couples, and 52 percent of different-sex couples lived outside of Massachusetts. The sample was predominantly non-Hispanic White $(n=651,86.11 \%)$, followed by Hispanic $(n=33,3.57 \%)$, non-Hispanic Black $(n=27,3.57 \%)$, non-Hispanic Asian $(n=19,2.51 \%)$, non-Hispanic mixed race $(n=16,2.12 \%)$, non-Hispanic other $(n=9,1.19 \%)$ and non-Hispanic Native American $(n=$ $1,0.13 \%)$. All respondents identified as cisgender. The sample and results are not nationally representative, but the sample demographic characteristics are consistent with nationally representative data comparing same-sex and different-sex spouses in midlife on characteristics including age, relationship duration, place of residence, and education (Gates, 2015). 


\section{Measures}

Respondents were asked a series of survey questions about a time in their relationship when their spouse experienced their highest level of psychological distress. They were asked about how they responded in terms of providing support, how this distress impacted them, and how the distress impacted their relationship.

\section{[Insert Table 1 about here]}

Provisions of support. Respondents were asked single items about whether they did each of the following never, rarely, sometimes, or often (range: 1-4) in reaction to their spouse's perceived distress: tried to help spouse get a better perspective, gave spouse time or space to themselves, took care of tasks spouse normally handles, and encouraged spouse to talk about feelings. Items were developed based on the Dyadic Coping Inventory (Bodenmann, 2008) and previous in-depth interviews (Reczek et al., 2020; Thomeer et al., 2013; Umberson et al., 2017). Specific items were chosen in order to emphasize and investigate gendered ways of providing support. When considered together as a composite scale, the items we included had an alpha of 0.50. We considered items separately both because of this alpha and because of our research focus.

Personal and marital stress levels. Respondents were also asked two single items on how stressful their spouse's distress was for them personally and how stressful their spouse's distress was for their marriage, with the options of not at all, slightly, somewhat, very, and extremely (range: $1-5)$.

Covariates. As covariates in all models, we controlled for relationship duration (years lived together), educational attainment of respondent $(0=$ less than college degree, $1=$ college degree), age of respondent, any children in household, and whether the respondent was working 
full-time. We also controlled for time since the distress occurred (less than 1 year ago, 1 to 2 years ago, 3 to 4 years ago, 5 or more years ago), and whether the distress ongoing (yes/no). We included relationship quality, measured with the four item $(\alpha=.92)$ Couples Satisfaction Index (Funk \& Rogge, 2007), which asked participants to rate their relationship quality with items such as, "I have a warm and comfortable relationship with my partner" on a scale from 1 (not at all true) to 6 (completely true). These controls have each been found to be correlated with experiences of distress and support within relationships (Garcia \& Umberson, 2019). In addition, because of its possible association with responses to a spouse's distress, we controlled for the respondent's depressive symptoms, measured with an 11-item version of the Center for Epidemiological Studies Depression Scale (CES-D). Reponses ranged from 0 (rarely/none of the time) to 3 (most of the time) (range: 0-27, with higher values indicating more depressive symptoms; $\alpha=.85$ ). We show correlations between study variables in Tables 2 and 3.

[Insert Table 2 about here]

[Insert Table 3 about here]

\section{Analysis}

We conducted descriptive analyses in Stata 15 to answer our first two research questions about how people provide support when their spouse is distressed and how support varies by their own gender, their spouse's gender, and whether they are in a same-sex or different-sex couple. After calculating these descriptive statistics, regression analyses proceeded in two steps. We examined the main effects of gender, spouse gender, and whether couples were in a same- or different-sex marriage for respondents' predicted support responses to distress in a multilevel modeling framework with Stata's mixed command to account for the nested nature of the data 
(i.e., spouses nested within dyads). To account for the interdependence of dyads, we used a compound symmetry error structure in which the models constrained each spouse's residual errors to be equal and estimated one shared dyad covariance. This error structure provides conservative estimates when dyads are distinguishable (i.e., different-sex dyads); these estimates are preferred over bias that would be introduced by using other error structures such as heterogeneous compound symmetry (i.e., one shared covariance but errors are not constrained to be equal) with indistinguishable (i.e., same-sex) dyads (Kenny et al., 2006). We compared support outcomes by gender relational context using the factorial method (West et al., 2008) in which we include respondent gender $(0=$ man, $1=$ woman $)$, spouse gender $(0=$ man, $1=$ woman $)$, and the interaction between respondent gender and spouse gender $(0=$ same-sex dyad, 1=different-sex dyad). All models include controls for the covariates discussed above. We examined statistical differences in model predicted reports of support responses to distress between couple types using Wald tests. To answer our third research question about whether support depends on the extent to which a spouse's distress is perceived to be personally or maritally stressful for respondents, we took a similar approach as above, but added to the models personal stress levels and marital stress levels and estimated these coefficients.

To answer our fourth research question, how gender relational context moderate the associations between whether a spouse's psychological distress was relationally and/or personally stressful and support responses to distress, we used a multiple group framework in Mplus 8.4. These models are statistically identical to the models analyzed using mixed (i.e., they account for the interdependence of spouses nested within dyads using a compound symmetry error structure); however, the multiple group models simplify the 3-way interaction of the 
moderation analyses by simultaneously but independently estimating each model for male samesex couples, different-sex couples, and female same-sex couples.

\section{Results}

First, we asked, how do respondents provide support for their spouse when their spouse is experiencing psychological distress (i.e., trying to change perspective, giving time and space, taking care of spouse's normal tasks, encouraging spouse to talk), and how does this provision of support differ by own gender, spouse's gender, and whether in same-sex or different-sex couple? As shown in the descriptive statistics in Table 1, the least common pattern of support was taking care of the spouse's normal tasks. In terms of gender differences, in the regression models in Table 4 controlling for key variables, we found no statistical differences across gender groups in reports of trying to change their spouse's perspective when their spouse was distressed. There were, however, differences across respondents by gender relational contexts in the remaining three categories of support. Women in different-sex couples reported giving their distressed spouse time and space and taking care of their spouse's normal tasks less often than all other respondent groups (men and women in same-sex couples and men in different-sex couples). In contrast, men in different-sex couples reported encouraging their distressed spouse to talk less often than all other respondent groups.

[Insert Table 4 about here]

Next, we asked, do support provisions vary in relation to how stressful the respondent's spouse's distress was for the respondent personally and how stressful their spouse's distress was for the marriage? And do these patterns vary by the respondent's own gender, their spouse's gender, and whether they are in a same-sex or different-sex couple? As shown in Table 4, based on results from the regression analysis, being personally distressed by a spouse's distress was 
positively associated with respondents giving their spouse time or space to themselves, taking care of tasks their spouse normally handles, and encouraging their spouse to talk about their feelings. On the other hand, feeling a spouse's distress was stressful for the relationship was negatively associated with the respondent providing support for the distressed spouse by giving time and space and encouraging to talk. Thus, there are countervailing trends- - feeling that the spouse's psychological distress was stressful for the respondent was positively associated with the extent to which the respondent reported providing support for their spouse but feeling it was stressful for their marriage was negatively associated with support expressions. Notably, taking care of the distressed spouse's normal tasks was only positively associated with the spouse's distress being personally stressful for the respondent and not related to marital stress levels.

[Insert Table 5 about here]

Finally, we considered whether the association between the perceived stress impact from a spouse's distress and the support provided by the respondent depended on the gender relational context. The multiple group regression analyses showed that couple type (i.e., same-sex or different-sex couple, gender of both spouses) did not moderate most of the associations, suggesting the pattern of results was similar across respondents whether they are men married to men, men married to women, women married to women, or women married to men. But a few of these patterns were conditioned on gender of the respondent, the gender of the spouse, and whether in a same-sex or different-sex marriage, discussed in detail below. We show the estimates for support provision by the respondent when the spouse's distress was perceived as stressful for the respondent personally in Figure 1 and when the respondent felt the spouse's distress was stressful for the relationship in Figure 2. Full model estimates of the moderation analyses are available in supplementary materials (Tables S1 and S2). A spouse's psychological 
distress being personally stressful for the respondent was associated with an increase in giving more time and space and encouraging the distressed spouse to talk only for women married to men and an increase in taking care of their partner's normal tasks only for women married to women. A spouse's psychological distress being perceived by the respondent to be stressful for the marriage was negatively associated with taking care of partner's normal tasks and encouraging a partner to talk only for women married to women.

[Insert Figure 1 about here]

[Insert Figure 2 about here]

\section{Discussion}

We considered how support is provided in response to perceptions about a spouse's psychological distress and the gender dynamics of support within same-sex and different-sex marriages. This study provides insight into gendered emotional support dynamics, psychological distress processes within marriages, and differences and similarities across same-sex and different-sex couples. We emphasize three major themes from our analysis, discussed in detail below. In presenting each of these themes, we highlight the importance of a dyadic perspective on distress and support in order to contextualize gender patterns within marriage. Additionally, in interpreting these findings, we recognize the privilege of our sample, as a majority White and college-educated, all married and cisgender group, and situate our findings within this hegemonic context, calling for future studies to move beyond heteronormative and White-centric frameworks (Allen \& Mendez, 2018).

Our first major theme addresses why differences in support provision within and across gender groups (e.g., men married to women compared to women married to men; men married to men compared to men married to women) exist and how they are sustained. Specifically, 
recognizing and understanding these relationship dynamic requires a dyadic and gendered lens (Thomeer et al., 2020). For example, we found that women in different-sex relationships were least likely to support their spouse by taking care of some of their spouse's tasks when their spouse was distressed. Rather than seeing this dynamic as solely reflecting constructions of women and femininity, a dyadic and gendered lens emphasizes how women's gender performances within different-sex relationships intersect with their husband's enactments of masculinity. Thus, less frequent reports of taking over a spouse's normal tasks by women in different-sex relationships, compared to women in same-sex relationships and men, may reflect previous research showing that men in different-sex relationships-especially in this current midlife cohort and relatively privileged sample (e.g., majority White and college-educated, cisgender)_-do less housework than women in different-sex couples and men and women in same-sex couples (Solomon et al., 2005). In this way, women in different-sex couples may take over less of their spouse's household tasks when he is distressed because he does fewer tasks to begin with. We emphasize that consideration of one spouse's gender without also identifying the gender of the other spouse might lead us to overlook these gendered support dynamics.

A dyadic and gendered lens also draws attention to the relative lack of gender differences when comparing men and women across same-sex couples, in sharp contrast to the gender differences found within different-sex couples, a finding that is consistent with previous studies (Prickett et al., 2015; Reczek et al., 2020). This may reflect that men and women in same-sex relationships draw on more diverse constructions of gender and have less power-based divisions (Goldberg \& Smith, 2013). A recent study considering when and how spouses encourage each other to seek professional help for psychological distress and other mental health issues found that same-sex couples generally took a more intentional approach (e.g., making the appointment 
for their spouse, working to convince spouse to take medications) whereas different-sex couples had a more "hands-off" strategy (Reczek et al., 2020). A dyadic and gendered lens calls attention to how gender may be enacted differently within these different marital contexts.

The second major theme from our results is that provision of support to a spouse when that spouse is experiencing high levels of distress reflect the stress experiences of both spousesboth personal and marital stress. This finding supports a dyadic perspective of stress and support which views spousal dynamics as inextricably linked such that one's spouse's stress impacts the other spouse's well-being and stress response (Bodenmann, 1997). Notably, we found that more support is provided when the spouse's distress is perceived as personally stressful for the respondent, but less support is provided when the spouse's distress is perceived as stressful for the relationship. The respondent's personal stress may be linked to higher levels of support provision because personal stress is related to the severity of the spouse's distress, and more severe distress provokes more support. Alternatively, we speculate that providing support when distress is personally stressful is a way for respondents to have some control or to address their partner's distress in a way that benefits them both (thus reducing their personal stress). In contrast, marital stress levels from a spouse's perceived psychological distress were associated with lower levels of support. Thus, in contrast to our finding with personal stress, if a spouse's distress is already straining their relationship, support from the other spouse might not improve it, or the potential support provider might not feel compelled to provide support. This finding demonstrates the complexities associated with support provision—especially support in response to a spouse's psychological distress and mental health issues (Oute \& Huniche, 2017). We are unable to make causal inferences regarding this finding, as psychological distress can both cause strain in relationships and be caused by strain in relationships (Meyer et al., 2019). 
Yet these findings must also be examined through a dyadic and gendered lens. We find that, compared to men, women's support provision is generally more impacted by their own feelings about personal and marital stress, in line with gender and emotion theories suggesting that women are more reactive to their own stress levels as well as to conflict and strain within marriage (Swinkels et al., 2019; Taylor, 2015). Specifically, marital stress levels may contribute to less support provision by women, as suggested by prior research indicating that women are more aware of and more burdened when strain enters the relationship (Ogolsky et al., 2017). Future studies should attempt to identify the mechanisms behind these gendered dynamics in support provision and distress.

Our third major theme is that differences between men and women within same- and different-sex relationships need to be contextualized alongside the many similarities of these groups, with both these similarities and differences reflecting broader intersectional forces. Rather than approaching studies of men and women within marriage from a frame of difference, studies should also address similarities across groups and recognize the cultural and structural sources of these similarities. The similarities found within our study are likely driven by broader discourses and norms around providing support within marriage, especially in times of psychological and emotional need (Cherlin, 2009). The expectation to care for a spouse "in sickness and in health" likely has resonance for men and women in both same- and different-sex marriages, as indicated by the high levels of support reported in our study.

Yet these similarities may also reflect the hegemonic and privileged status of the couples in our sample (Allen \& Mendez, 2018). Although we include same-sex couples, it is still the case that the dynamics we identify are largely built on heteronormative assumptions, based on norms of binary gender constructions (i.e., men and women as the only gender identities) and 
heterosexual orientation (i.e., man partnered with woman as the only relationship type; Fish \& Russell, 2018). An intersectional perspective understands social processes as reflecting complex interdependent systems of power and privilege (Collins, 2015; Few-Demo, 2014), and our sample generally benefits from this system, through opportunities and advantages predicated on their racial, class, and marital privilege, likely facilitating the provision of support within their relationships (Allen \& Mendez, 2018; Berger \& Carlson, 2020). Although our data do not allow us to identify the specific ways that this power and privilege impacts the results, we recognize the importance of this broader context in shaping within-couple gender dynamics of support and distress.

\section{Limitations and Future Directions}

Our findings should be interpreted in light of several limitations. The primary limitation was discussed above and relates to the sociodemographic composition of our sample. In considering how this relatively advantaged group of couples provides support to a spouse experiencing psychological distress, we do not argue that the findings would be generalizable to other populations. Additionally, all respondents in this sample are cisgender, and our measures of gender are dichotomizing, ignoring components of gender outside of identity and missing experiences of nonbinary or gender nonconforming people. Future studies should include more comprehensive measures of gender and more diverse samples. We also do not include measures of sexual orientation; these processes may differ depending on whether respondents are heterosexual, bisexual, pansexual, asexual, gay, lesbian, or another orientation.

As a second limitation, our data are cross-sectional and thus our findings should not be interpreted as causally linked. Longitudinal data can provide greater insight into how support and psychological distress processes unfold over time. For example, longitudinal data provides an 
opportunity to explore the role of selection in the associations between relationships, gender, and psychological distress. Additionally, we are not able to consider the unique impact of age or cohort. Our study involves midlife couples (ages 35 to 65), and dynamics of support may differ if focusing on different age groups or cohorts. Third, related to issues of recall bias, respondents are providing information on past experiences of distress, and it may be that respondents overestimate the amount of support they provided. Respondents provide information regarding what they perceive as their spouse's highest level of psychological distress, but our preliminary analysis suggests that this differs from the period that their spouse identified. Importantly, provisions of support around a spouse's psychological distress are predicated on perceiving that the spouse is distressed. Yet one spouse's distress may go unnoticed, for example, if the distressed spouse obscures their own distress or if the other spouse is dismissive or inattentive (Thomeer et al., 2013). The extent to which the distress is acknowledged clearly shapes how support is expressed, and these processes are likely gendered.

Finally, our models do not include the source of the spouse's psychological distress, a limitation especially given our focus on two groups at heightened risk for psychological distress (Almeida \& Kessler, 1998; Meyer \& Frost, 2013). Women's higher distress levels compared to men are hypothesized to be due to women's greater exposure to sexism at the individual, interactional, and institutional levels (Homan, 2019). People in same-sex relationships also tend to report higher levels of psychological distress than people in different-sex relationships, and, according to the minority stress model, this is due to the unique minority stressors experienced by people in same-sex relationships that emanate from the experience of being stigmatized and discriminated against by the larger society (Meyer \& Frost, 2013). Psychological distress stemming from sexism or minority stressors may be linked to spousal support differently than 
distress with other origins - including distress caused by marital issues (Garcia \& Umberson, 2019). In cases of psychological distress from minority stressors, support provided by a spouse may be especially salient whereas an absence of support may serve to exacerbate gender- and sexuality-based inequalities (Guschlbauer et al., 2019). We recommend future studies consider how the origin of psychological distress might shape relationship processes.

\section{Conclusion}

Support provision in marriage has been extensively studied in the context of different-sex couples (Monin et al., 2019; Thomeer et al., 2013) and, to a lesser extent, same-sex couples (Bouaziz et al., 2013; Umberson et al., 2017). But past studies miss how support might differ across gendered relational contexts, especially if using an individual level rather than a dyadic perspective, despite the fact that stress and support are relational (Bodenmann, 1997). Even though support within relationships is generally understood as beneficial for emotional wellbeing and mental health (Thoits, 2011), we suggest that this benefit is likely conditioned on multiple factors - including the gendered and dyadic context and the extent to which a spouse's distress is personally and maritally distressing. Unlike support around more debilitating physical or mental health conditions, support in response to a spouse's distress may be viewed as a routine relationship dynamic; yet, providing support in response to a spouse's psychological distress can be emotionally and physically taxing for the support provider even if it is beneficial for the person receiving the support (Oute \& Huniche, 2017). When inadequate levels of support are provided, intimate relationships may be an obstacle to psychological well-being, exacerbating psychological distress and increasing the risk for chronic and recurrent depression or other mental health issues (Hammen, 2006). This outcome is likely exacerbated when considering populations facing high levels of societal disadvantage and discrimination, such as 
transgender and gender nonconforming people, cohabiting couples, and couples of color (Allen \& Mendez, 2018). Regardless of context, a gendered and dyadic perspective on psychological distress within marriage provides needed insight into the necessary relationship maintenance processes that best support spouses across marital contexts (Ogolsky et al., 2017; Randall \& Messerschmitt-Coen, 2019). 


\section{References}

Allen, S. H., \& Mendez, S. N. (2018). Hegemonic heteronormativity: Toward a new era of queer family theory. Journal of Family Theory \& Review, 10(1), 70-86. https://doi.org/10.1111/jftr.12241

Almeida, D. M. \& Kessler, R. C. (1998). Everyday stressors and gender differences in daily distress. Journal of Personality and Social Psychology, 75(3), 670-680. https://doi.org/10.1037/0022-3514.75.3.670

Berger, L. M., \& Carlson, M. J. (2020). Family policy and complex contemporary families: A decade in review and implications for the next decade of research and policy practice. Journal of Marriage and Family, 82(1), 478-507. https://doi.org/10.1111/jomf.12650

Bodenmann, G. (1997). Dyadic coping-a systematic-transactional view of stress and coping among couples: Theory and empirical findings. European Review of Applied Psychology, 47, 137-140.

Bodenmann, G. (2008). Dyadisches Coping Inventar: Test manual [Dyadic Coping Inventory: Test manual]. Bern, Switzerland: Huber.

Bouaziz, A.-R., Lafontaine, M.-F., Gabbay, N., \& Caron, A. (2013). Investigating the validity and reliability of the caregiving questionnaire with individuals in same-sex couple relationships. Journal of Relationships Research, 4, e2. https://doi.org/10.1017/jrr.2013.2

Cherlin, A. (2009). Marriage, divorce, remarriage. Harvard University Press.

Collins, P. H. (2015). Intersectionality's definitional dilemmas. Annual Review of Sociology, 41, 1-20. https://doi.org/10.1146/annurev-soc-073014-112142

Connell, R. W. \& Messerschmidt, J. W. (2005). Hegemonic masculinity: Rethinking the concept. Gender \& Society, 19(6), 829-859. https://doi.org/10.1177/0891243205278639 
Few-Demo, A. L. (2014). Intersectionality as the "new" critical approach in feminist family studies: Evolving racial/ethnic feminisms and critical race theories. Journal of Family Theory \& Review, 6(2), 169-183. https://doi.org/10.1111/jftr.12039

Fish, J. N. \& Russell, S. T. (2018). Queering methodologies to understand queer families. Family Relations, 67(1), 12-25. https://doi.org/10.1111/fare.12297

Funk, J. L., \& Rogge, R. D. (2007). Testing the ruler with item response theory: increasing precision of measurement for relationship satisfaction with the Couples Satisfaction Index. Journal of Family Psychology, 21(4), 572-583. https://doi.org/10.1037/08933200.21 .4 .572

Garcia, M. A., \& Umberson, D. (2019). Marital strain and psychological distress in same-sex and different-sex couples. Journal of Marriage and Family, 81(5), 1253-1268. https://doi.org/10.1111/jomf.12582

Gates, G. J. (2015). Demographics of married and unmarried same-sex couples: Analyses of the 2013 American Community Survey. Los Angeles: The Williams Institute, UCLA School of Law.

Goldberg, A. E. \& Smith, J. Z. (2013). Predictors of psychological adjustment in early placed adopted children with lesbian, gay, and heterosexual parents. Journal of Family Psychology, 27(3), 431-442. https://doi.org/10.1037/a0032911

Guschlbauer, A., Smith, N. G., DeStefano, J., \& Soltis, D. E. (2019). Minority stress and emotional intimacy among individuals in lesbian and gay couples: Implications for relationship satisfaction and health. Journal of Social and Personal Relationships, 36(3), 855-878. https://doi.org/10.1177/0265407517746787 
Hammen, C. (2006). Stress generation in depression: Reflections on origins, research, and future directions. Journal of Clinical Psychology, 62(9), 1065-1082. https://doi.org/10.1002/jclp.20293

Homan, P. (2019). Structural sexism and health in the United States: A new perspective on health inequality and the gender system. American Sociological Review, 84(3), 486-516. https://doi.org/10.1177\%2F0003122419848723

Kenny, D. A., Kashy, D. A., \& Cook, W. L. (2006). Dyadic data analysis. Guilford Press.

Meyer, D., Kemper-Damm, B., Parola, F., \& Salas, J. (2019). Depressive symptoms as a predictor of men's relationship satisfaction. The Family Journal, 27(1), 37-43. https://doi.org/10.1177/1066480718809058

Meyer, I. H. \& Frost, D. M. (2013). Minority stress and the health of sexual minorities. C. J. Patterson \& A. R. D'Augelli (Eds.), Handbook of Psychology and Sexual Orientation (pp. 252-266). Oxford University Press.

Monin, J. K., Levy, B., Doyle, M., Schulz, R., \& Kershaw, T. (2019). The impact of both spousal caregivers' and care recipients' health on relationship satisfaction in the Caregiver Health Effects Study. Journal of Health Psychology, 24(12):1744-1755. https://doi.org/10.1177\%2F1359105317699682

Ogolsky, B. G., Monk, J. K., Rice, T. M., Theisen, J. C., \& Maniotes, C. R. (2017). Relationship maintenance: A review of research on romantic relationships. Journal of Family Theory \& Review, 9(3), 275-306. https://doi.org/10.1111/jftr.12205

Oute, J. \& Huniche, L. (2017). Who gets involved with what? A discourse analysis of gender and caregiving in everyday family life with depression. Outlines: Critical Practice Studies, $18(1), 5-27$. 
Prickett, K. C., A. Martin-Storey, \& Crosnoe, R. (2015). A research note on time with children in different- and same-sex two-parent families. Demography, 52(3), 905-918. https://doi.org/10.1007/s13524-015-0385-2

Proulx, C. M., Ermer, A. E., \& Kanter, J. B. (2017). Group-based trajectory modeling of marital quality: A critical review. Journal of Family Theory \& Review, 9(3), 307-327. https://doi.org/10.1111/jftr.12201

Randall, A. K., \& Messerschmitt-Coen, S. (2019). Dyadic coping as relationship maintenance. In Relationship Maintenance: Theory, Process, and Context (pp. 178-193). Cambridge University Press. Doi: 10.1017/9781108304320.010

Reczek, C., Thomeer, M. B., Gebhardt-Kram, L., \& Umberson, D. (2020). "Go see somebody”: How spouses promote mental health care. Society and Mental Health, 10(1), 80-96. https://doi.org/10.1177\%2F2156869319834335

Risman, B. J. (2004). Gender as a social structure: Theory wrestling with activism. Gender \& Society, 18(4), 429-450. https://doi.org/10.1177/0891243204265349

Simon, R. W. \& Nath, L. E. (2004). Gender and emotion in the United States: Do men and women differ in self-reports of feelings and expressive behavior? American Journal of Sociology, 109(5), 1137-1176. https://doi.org/10.1086/382111

Solomon, S. E., Rothblum, E. D., \& Balsam, K. F. (2005). Money, housework, sex, and conflict: Same-sex couples in civil unions, those not in civil unions, and heterosexual married siblings. Sex Roles, 52(9-10), 561-575. https://doi.org/10.1007/s11199-005-3725-7

Swinkels, J., van Tilburg, T., Verbakel, E., \& van Groenou, M. B. (2019). Explaining the gender gap in the caregiving burden of partner caregivers. Journals of Gerontology Series B, 74(2), 309-317. https://doi.org/10.1093/geronb/gbx036 
Taylor, J. (2015). Gender orientation and the cost of caring for others. Society and Mental Health, 5(1), 49-65. https://doi.org/10.1177\%2F2156869314562966

Thoits, P. A. (2011). Mechanisms linking social ties and support to physical and mental health. Journal of Health and Social Behavior, 52(2), 145-161. https://doi.org/10.1177\%2F0022146510395592

Thomeer, M. B., Umberson, D., \& Pudrovska, T. (2013). Marital processes around depression: A gendered and relational perspective. Society and Mental Health, 3(3), 151-169. https://doi.org/10.1177\%2F2156869313487224

Thomeer, M. B., Reczek, C., \& Umberson, D. (2015). Relationship dynamics around depression in gay and lesbian couples. Social Science \& Medicine, 147, 38-46. https://doi.org/10.1016/j.socscimed.2015.10.048

Thomeer, M. B., Umberson, D., \& Reczek, C. (2020). The gender-as-relational approach for theorizing about romantic relationships of sexual and gender diverse mid- to later-life adults. Journal of Family Theory \& Review, 12(2), 220-237. https://doi.org/10.1111/jftr.12368

Thomeer, M. B., \& Ostergren Clark, K. (2021). The development of gendered health-related support dynamics over the course of a marriage. Journal of Women \& Aging, 1-17. https://doi.org/10.1080/08952841.2020.1826624

Umberson, D., Thomeer, M. B., Kroeger, R. A., Reczek, C., \& Donnelly, R. (2017). Instrumental- and emotion-focused care work during physical health events: Comparing gay, lesbian, and heterosexual marriages. Journals of Gerontology Series B, 72(3), 498509. https://doi.org/10.1093/geronb/gbw133 
Umberson, D., Thomeer, M. B., Pollitt, A. M., \& Mernitz, S. E. (2020). The psychological toll of emotion work in same-sex and different-sex marital dyads. Journal of Marriage and Family, 82(4), 1141-1158. https://doi.org/10.1111/jomf.12686

West, C. \& Zimmerman, D. H. (1987). Doing gender. Gender \& Society, 1(2), 125-151. https://doi.org/10.1177\%2F0891243287001002002

West, T. V., Popp, D., \& Kenny, D. A. (2008). A guide for the estimation of gender and sexual orientation effects in dyadic data: An Actor-Partner Interdependence Model approach. Personality and Social Psychology Bulletin, 34(3), 321-336.

https://doi.org/10.1177\%2F0146167207311199 
Table 1

Descriptive Statistics of Covariates and Study Variables by Gender Relational Contexts

\begin{tabular}{|c|c|c|c|c|c|c|c|c|}
\hline \multirow[b]{2}{*}{ Covariates } & \multicolumn{2}{|c|}{$\begin{array}{l}\text { Men with Men } \\
\quad(\mathrm{n}=212)\end{array}$} & \multicolumn{2}{|c|}{$\begin{array}{l}\text { Men with } \\
\text { Women } \\
(\mathrm{n}=115)\end{array}$} & \multicolumn{2}{|c|}{$\begin{array}{c}\text { Women with } \\
\text { Men } \\
(\mathrm{n}=115)\end{array}$} & \multicolumn{2}{|c|}{$\begin{array}{l}\text { Women with } \\
\text { Women } \\
(\mathrm{n}=314)\end{array}$} \\
\hline & $\mathrm{n}$ & $\%$ & $\mathrm{n}$ & $\%$ & $\mathrm{n}$ & $\%$ & $\mathrm{n}$ & $\%$ \\
\hline College degree or more & 170 & 80.19 & 80 & 69.57 & 87 & 75.65 & 271 & 86.31 \\
\hline Any children in household & 27 & 12.74 & 82 & 71.30 & 82 & 71.3 & 127 & 40.45 \\
\hline Working full-time & 162 & 76.42 & 87 & 75.65 & 65 & 56.52 & 232 & 73.89 \\
\hline \multirow[t]{2}{*}{ Distress event currently ongoing } & 55 & 26.07 & 56 & 49.12 & 34 & 29.57 & 119 & 37.90 \\
\hline & $\mathrm{M}$ & $\mathrm{SD}$ & $\mathrm{M}$ & $\mathrm{SD}$ & $\mathrm{M}$ & $\mathrm{SD}$ & $\mathrm{M}$ & $\mathrm{SD}$ \\
\hline Time since distress event occurred (range 1-4) & 2.84 & 1.19 & 2.76 & 1.14 & 2.93 & 1.14 & 2.77 & 1.17 \\
\hline Relationship duration (years lived together; range 3-45) & $16.23^{\mathrm{d}}$ & 7.79 & $15.89^{\mathrm{d}}$ & 8.16 & $15.89^{\mathrm{d}}$ & 8.16 & $13.73^{\mathrm{abc}}$ & 7.69 \\
\hline Relationship quality (range 1-6) & $5.21^{\mathrm{bc}}$ & 0.88 & $4.88^{\mathrm{ad}}$ & 1.04 & $4.89^{\mathrm{a}}$ & 1.07 & $5.16^{\mathrm{b}}$ & 0.86 \\
\hline Age (range $35-65)$ & 49.72 & 8.46 & 46.48 & 8.11 & 45.04 & 7.62 & 49.00 & 8.41 \\
\hline Depressive symptoms (range $0-27$ ) & 16.57 & 5.10 & 17.02 & 5.40 & 17.92 & 5.23 & 17.09 & 5.37 \\
\hline \multicolumn{9}{|l|}{ Key study variables } \\
\hline Support provision (range 1-4) & $\mathrm{M}$ & $\mathrm{SD}$ & M & SD & $\mathrm{M}$ & SD & M & SD \\
\hline Respondent tried to change distressed spouse's perspective & $3.63^{b}$ & 0.54 & $3.44^{\mathrm{a}}$ & 0.61 & 3.49 & 0.71 & 3.59 & 0.57 \\
\hline Respondent gave distressed spouse time and space & $3.45^{\mathrm{c}}$ & 0.59 & 3.41 & 0.61 & $3.26^{\mathrm{ad}}$ & 0.61 & $3.44^{\mathrm{c}}$ & 0.56 \\
\hline Respondent took care of distressed spouse's normal tasks & 2.98 & 0.88 & 3.01 & 0.82 & $2.80^{\mathrm{d}}$ & 0.98 & $3.11^{\mathrm{c}}$ & 0.83 \\
\hline Respondent encouraged distressed spouse to talk & $3.50^{\mathrm{b}}$ & 0.69 & $3.25^{\text {acd }}$ & 0.83 & $3.56^{\mathrm{b}}$ & 0.65 & $3.55^{\mathrm{b}}$ & 0.62 \\
\hline \multicolumn{9}{|l|}{ Impact of distress (range 1-5) } \\
\hline How stressful spouse's distress was personally & 3.18 & 1.01 & 3.33 & 0.97 & 3.30 & 1.05 & 3.37 & 1.00 \\
\hline How stressful spouse's distress was relationally & 2.49 & 1.18 & 2.73 & 1.27 & 2.74 & 1.30 & 2.72 & 1.19 \\
\hline
\end{tabular}

Note. Support provision items were on a scale from never, rarely, sometimes, or often; impact of distress items were on a scale from not at all, slightly, somewhat, very, and extremely. ${ }^{a}$ significantly different $(\mathrm{p}<0.05)$ from men with men; ${ }^{\mathrm{b}}$ significantly different $(\mathrm{p}<$ $0.05)$ from men with women; ${ }^{c}$ significantly different $(\mathrm{p}<0.05)$ from women with men; ${ }^{d}$ significantly different $(\mathrm{p}<0.05)$ from women with women. 
Table 2

Correlations for Covariates and Study Variables for Men and Women in Different-Sex Couples

\begin{tabular}{|c|c|c|c|c|c|c|c|c|c|c|c|}
\hline Variables & 1 & 2 & 3 & 4 & 5 & 6 & 7 & 8 & 9 & 10 & 11 \\
\hline $\begin{array}{l}\text { (1) Time since distress event } \\
\text { occurred }\end{array}$ & -- & $0.26^{* *}$ & -0.08 & 0.06 & 0.04 & -0.02 & 0.08 & 0.18 & 0.10 & 0.12 & 0.10 \\
\hline (2) Relationship duration & 0.05 & -- & 0.01 & $0.60 * *$ & -0.14 & -0.10 & 0.05 & 0.08 & 0.00 & -0.09 & -0.14 \\
\hline (3) Relationship quality & -0.07 & -0.06 & -- & -0.09 & $-0.43 * *$ & 0.12 & -0.01 & 0.01 & 0.13 & 0.01 & $-0.23 *$ \\
\hline (4) Age & -0.03 & $0.70 * *$ & -0.01 & -- & -0.07 & 0.00 & 0.14 & -0.05 & -0.08 & -0.04 & -0.12 \\
\hline (5) Depressive symptoms & $-0.22 *$ & -0.14 & $-0.29 * *$ & $-0.24 *$ & -- & -0.02 & -0.04 & 0.05 & 0.03 & $0.27 * *$ & $0.27 * *$ \\
\hline $\begin{array}{l}\text { (6) Tried to change spouse's } \\
\text { perspective }\end{array}$ & -0.14 & -0.17 & 0.04 & -0.15 & -0.03 & -- & $0.41 * *$ & $0.20 *$ & $0.46^{* *}$ & 0.15 & 0.12 \\
\hline (7) Gave time and space & -0.02 & 0.06 & 0.01 & 0.11 & -0.11 & 0.17 & -- & $0.22 *$ & 0.14 & 0.14 & 0.02 \\
\hline $\begin{array}{l}\text { (8) Took care of spouse's } \\
\text { normal tasks }\end{array}$ & 0.07 & -0.11 & 0.01 & $-0.23 *$ & 0.10 & 0.18 & $0.22 *$ & -- & $0.40 * *$ & $0.19 *$ & 0.04 \\
\hline $\begin{array}{l}\text { (9) Encouraged spouse to } \\
\text { talk }\end{array}$ & -0.14 & $-0.19 *$ & 0.00 & -0.13 & 0.16 & $0.42 * *$ & $0.25^{* *}$ & $0.20^{*}$ & -- & 0.13 & 0.07 \\
\hline $\begin{array}{l}\text { (10) How stressful spouse's } \\
\text { distress was personally }\end{array}$ & 0.08 & 0.03 & -0.15 & 0.06 & $0.23 *$ & -0.02 & 0.17 & $0.19 *$ & $0.22 *$ & -- & $0.68 * *$ \\
\hline $\begin{array}{l}\text { (11) How stressful spouse's } \\
\text { distress was relationally }\end{array}$ & 0.12 & 0.00 & $-0.31 * *$ & -0.08 & $0.21 *$ & -0.10 & -0.02 & 0.15 & 0.02 & $0.66^{* *}$ & -- \\
\hline
\end{tabular}

Note. Correlations do not take into account the interdependence between dyad members and should be interpreted with caution.

Correlations for men in different-sex couples are above the diagonal; correlations for women in different-sex couples are below the diagonal.

$* p<0.05 ; * *<0.01$. 
Table 3

Correlations for Covariates and Study Variables for Male and Female Same-Sex Couples

\begin{tabular}{lcccccccccccc}
\hline Variables & 1 & 2 & 3 & 4 & 5 & 6 & 7 & 8 & 9 & 10 & 11 \\
\hline (1) Time since distress event occurred & -- & $0.29^{* *}$ & 0.08 & $0.27^{* *}$ & 0.02 & 0.03 & 0.11 & $-0.14^{*}$ & -0.04 & 0.10 & 0.08 \\
(2) Relationship duration & $0.29^{* *}$ & -- & 0.04 & $0.58^{* *}$ & -0.04 & -0.04 & 0.11 & 0.07 & -0.02 & $0.25^{* *}$ & 0.10 \\
(3) Relationship quality & 0.00 & 0.03 & -- & $0.14^{*}$ & $-0.44^{* *}$ & 0.11 & 0.07 & 0.04 & 0.10 & -0.10 & $-0.29^{* *}$ \\
(4) Age & $0.20^{* *}$ & $0.54^{* *}$ & 0.00 & -- & -0.10 & 0.05 & 0.04 & -0.02 & -0.02 & $0.18^{* *}$ & -0.10 \\
(5) Depressive symptoms & -0.11 & 0.04 & $-0.40^{* *}$ & -0.02 & -- & -0.05 & -0.02 & 0.05 & 0.04 & 0.13 & $0.22^{* *}$ \\
(6) Tried to change spouse's perspective & -0.05 & -0.01 & $0.30^{* *}$ & 0.05 & -0.06 & -- & $0.19^{* *}$ & $0.19^{* *}$ & $0.27^{* *}$ & 0.06 & -0.04 \\
(7) Gave time and space & -0.03 & 0.04 & $0.11^{*}$ & 0.07 & 0.01 & $0.23^{* *}$ & -- & 0.11 & 0.13 & 0.07 & -0.04 \\
(8) Took care of spouse's normal tasks & -0.02 & 0.03 & -0.05 & -0.10 & 0.04 & $0.17^{* *}$ & $0.13^{*}$ & -- & $0.22^{* *}$ & 0.09 & 0.06 \\
(9) Encouraged spouse to talk & 0.04 & 0.03 & $0.25^{* *}$ & -0.03 & -0.08 & $0.36^{* *}$ & $0.12^{*}$ & $0.16^{* *}$ & -- & -0.02 & -0.06 \\
(10) How stressful spouse's distress was & -0.02 & 0.04 & $-0.19^{* *}$ & 0.01 & $0.21^{* *}$ & -0.01 & -0.03 & $0.12^{*}$ & -0.03 & -- & $0.56^{* *}$ \\
personally & & & & & & & & & & \\
(11) How stressful spouse's distress was & 0.03 & -0.03 & $-0.34^{* *}$ & -0.08 & $0.20^{* *}$ & $-0.12^{*}$ & -0.08 & -0.01 & $-0.16^{* *}$ & $0.59^{* *}$ & --
\end{tabular}

Note. Correlations do not take into account the interdependence between dyad members and should be interpreted with caution.

Correlations for male same-sex couples are above the diagonal; correlations for female same-sex couples are below the diagonal. $* p<0.05 ; * * p<0.01$. 
Table 4

Regression Model Predicted Marginal Means of How Responded to Spouse's Distress by Gender Relational Contexts, According to Respondent

\begin{tabular}{|c|c|c|c|c|c|c|c|c|}
\hline & \multicolumn{2}{|c|}{$\begin{array}{l}\text { Men with } \\
\text { Men } \\
(\mathrm{n}=212)\end{array}$} & \multicolumn{2}{|c|}{$\begin{array}{l}\text { Men with } \\
\text { Women } \\
(\mathrm{n}=115)\end{array}$} & \multicolumn{2}{|c|}{$\begin{array}{l}\text { Women with } \\
\text { Men } \\
(n=115)\end{array}$} & \multicolumn{2}{|c|}{$\begin{array}{l}\text { Women with } \\
\text { Women } \\
(\mathrm{n}=314)\end{array}$} \\
\hline & $\mathrm{M}$ & $\mathrm{SE}$ & $\mathrm{M}$ & $\mathrm{SE}$ & $\mathrm{M}$ & $\mathrm{SE}$ & $\mathrm{M}$ & $\mathrm{SE}$ \\
\hline $\begin{array}{l}\text { Respondent tried to change distressed spouse's } \\
\text { perspective }\end{array}$ & 3.59 & 0.04 & 3.50 & 0.06 & 3.54 & 0.06 & 3.57 & 0.03 \\
\hline Respondent gave depressed spouse time and space & $3.43^{\mathrm{c}}$ & 0.04 & $3.42^{\mathrm{c}}$ & 0.06 & $3.27^{\mathrm{abd}}$ & 0.06 & $3.44^{\mathrm{c}}$ & 0.03 \\
\hline $\begin{array}{l}\text { Respondent took care of distressed spouse's normal } \\
\text { tasks }\end{array}$ & $2.99^{c}$ & 0.06 & $2.99^{c}$ & 0.08 & $2.73^{\text {abd }}$ & 0.09 & $3.14^{\mathrm{c}}$ & 0.05 \\
\hline Respondent encouraged distressed spouse to talk & $3.48^{\mathrm{b}}$ & 0.05 & $3.28^{\mathrm{acd}}$ & 0.07 & $3.58^{b}$ & 0.07 & $3.55^{\mathrm{b}}$ & 0.04 \\
\hline
\end{tabular}

Note. ${ }^{\mathrm{a}}$ significantly different $(\mathrm{p}<0.05)$ from men with men; ${ }^{\mathrm{b}}$ significantly different $(\mathrm{p}<0.05)$ from men with women; ${ }^{\mathrm{c}}$ significantly different $(\mathrm{p}<0.05)$ from women with men; ${ }^{\mathrm{d}}$ significantly different $(\mathrm{p}<0.05)$ from women with women. Models control for relationship duration, educational attainment of respondent, age of respondent, whether any children in household, respondent's employment status, whether distress event currently ongoing, time since distress event occurred, relationship duration, relationship quality, and depressive symptoms of respondent and partner. 
Table 5

Regression Analysis Results of How Responded to Spouse's Distress Predicted by Gender Relational Context, Covariates, and How Personally and Maritally Stressful Spouse's Distress Was

\begin{tabular}{|c|c|c|c|c|}
\hline & $\begin{array}{l}\text { DV: Tried to } \\
\text { change perspective }\end{array}$ & $\begin{array}{c}\text { DV: Gave time } \\
\text { and space }\end{array}$ & $\begin{array}{c}\text { DV: Took care of } \\
\text { partner's normal tasks }\end{array}$ & $\begin{array}{l}\text { DV: Encouraged } \\
\text { to talk }\end{array}$ \\
\hline & $\mathrm{b}(\mathrm{SE})$ & $\mathrm{b}(\mathrm{SE})$ & $\mathrm{b}(\mathrm{SE})$ & $\mathrm{b}(\mathrm{SE})$ \\
\hline Respondent is woman & $-0.05(0.07)$ & $-0.17 *(0.07)$ & $-0.27 *(0.11)$ & $0.10(0.09)$ \\
\hline Spouse is woman & $-0.09(0.07)$ & $-0.01(0.07)$ & $-0.03(0.11)$ & $-0.19 *(0.09)$ \\
\hline Same-sex couple & $0.10(0.10)$ & $0.18(0.11)$ & $0.42 * *(0.16)$ & $0.13(0.13)$ \\
\hline College degree or more & $-0.008(0.05)$ & $0.01(0.05)$ & $0.07(0.08)$ & $0.13 *(0.06)$ \\
\hline Any children in household & $-0.11 *(0.05)$ & $-0.01(0.05)$ & $-0.01(0.08)$ & $-0.06(0.06)$ \\
\hline Working full-time & $0.01(0.05)$ & $-0.04(0.05)$ & $-0.07(0.07)$ & $0.07(0.06)$ \\
\hline Distress event currently ongoing & $0.03(0.05)$ & $0.06(0.05)$ & $0.04(0.07)$ & $0.03(0.06)$ \\
\hline Time since distress event occurred & $-0.008(0.02)$ & $0.01(0.02)$ & $-0.003(0.03)$ & $0.02(0.02)$ \\
\hline Relationship duration (years lived together) & $-0.008 *(0.003)$ & $0.002(0.003)$ & $0.01 *(0.005)$ & $-0.000(0.004)$ \\
\hline Relationship quality & $0.10 * *(0.03)$ & $0.03(0.03)$ & $0.006(0.04)$ & $0.10 * *(0.03)$ \\
\hline Age & $0.002(0.003)$ & $0.003(0.003)$ & $-0.02 * *(0.005)$ & $-0.005(0.004)$ \\
\hline Own depressive symptoms & $0.001(0.005)$ & $-0.001(0.004)$ & $0.004(0.007)$ & $0.01 *(0.005)$ \\
\hline Spouse's depressive symptoms & $0.001(0.004)$ & $0.002(0.004)$ & $0.007(0.006)$ & $0.002(0.005)$ \\
\hline How stressful spouse's distress was personally & $0.04(0.03)$ & $0.06^{*}(0.03)$ & $0.14 * *(0.04)$ & $0.07 *(0.03)$ \\
\hline How stressful spouse's distress was maritally & $-0.03(0.02)$ & $-0.05 *(0.02)$ & $-0.06(0.03)$ & $-0.06 *(0.03)$ \\
\hline Constant & $3.08 * *(0.29)$ & $3.06 * *(0.29)$ & $3.14 * *(0.43)$ & $2.75 * *(0.34)$ \\
\hline
\end{tabular}

${ }^{*} p<0.05 ; * * p<0.01$. 


\section{Figure 1}

Predicted Coefficient Estimates of the Association Between Respondents' Responses to a Spouse's Psychological Distress When the Distress is Personally Stressful by Gender Relationship Context

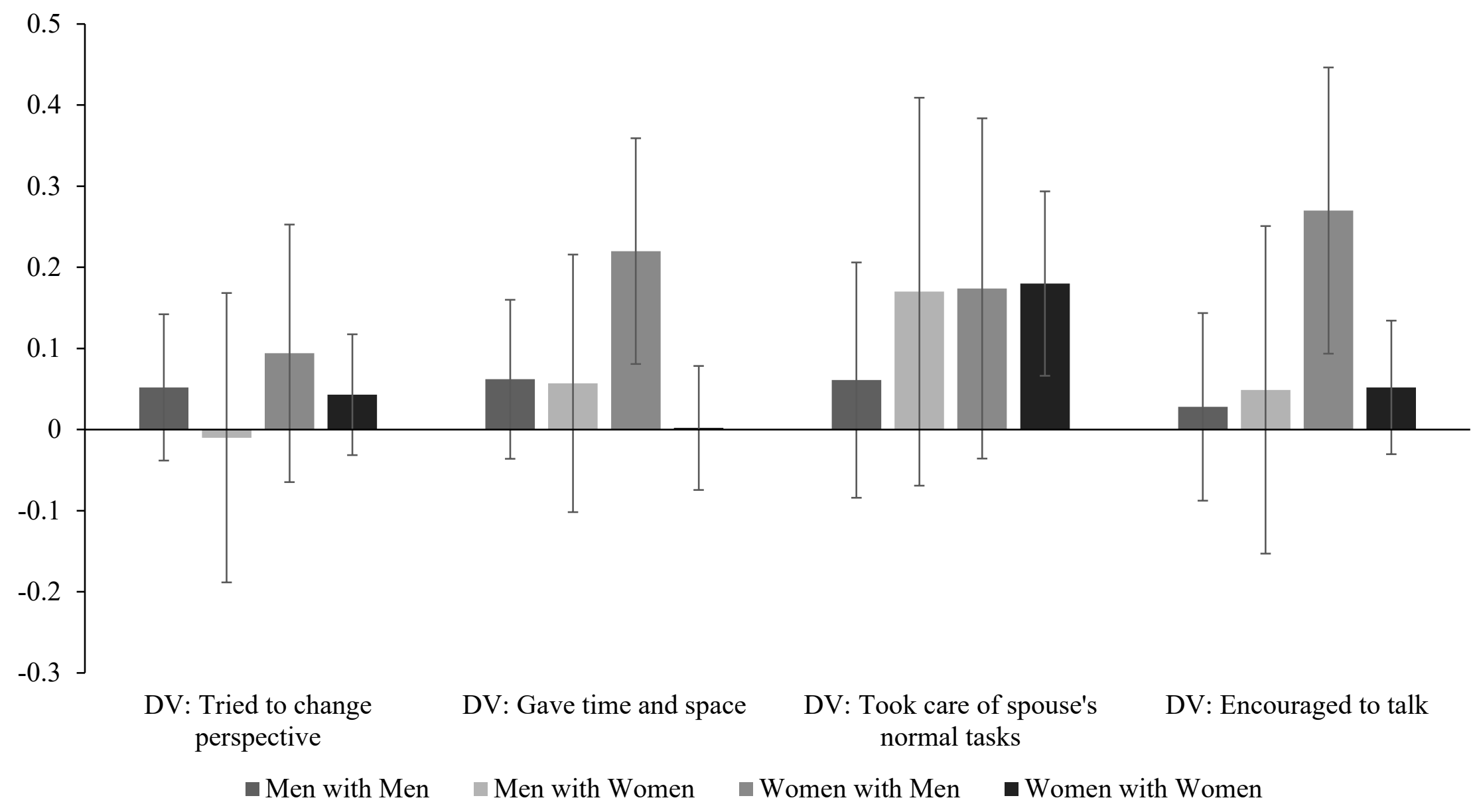




\section{Figure 2}

Predicted Coefficient Estimates of the Association Between Respondents' Responses to a Spouse's Psychological Distress When the Distress is Maritally Stressful by Gender Relationship Context

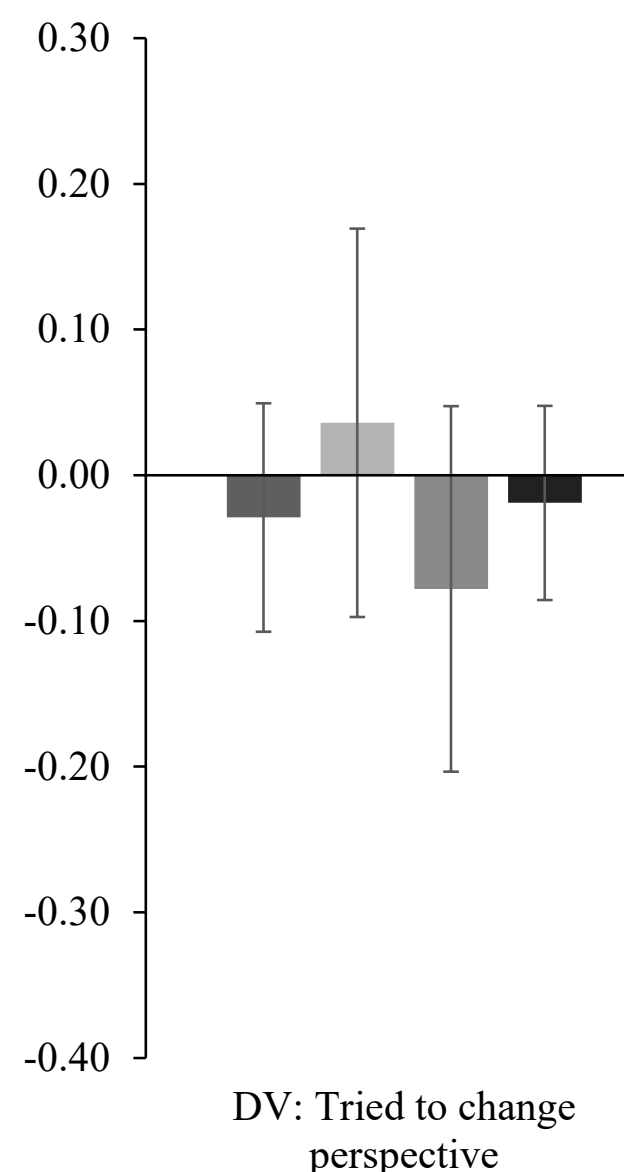
perspective
DV: Gave time and space

- Men with Men
Men with Women
Women with Men
DV: Took care of spouse's normal tasks

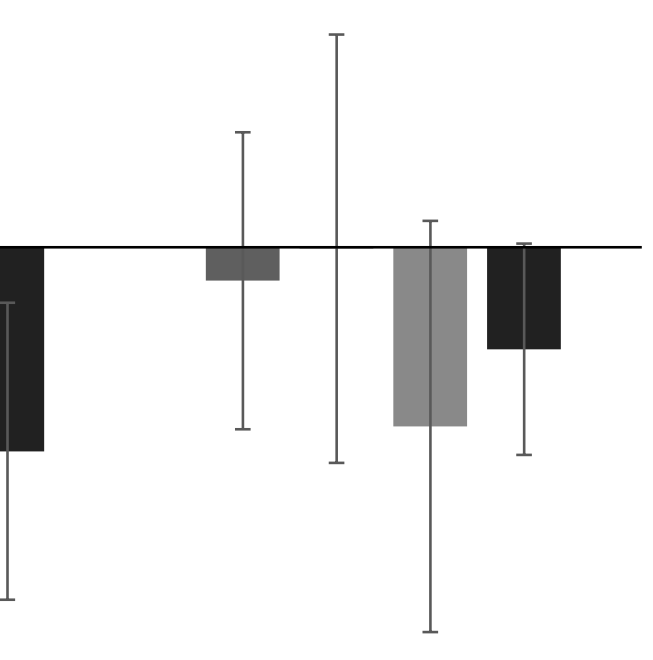

DV: Encouraged to talk 


\section{Supplementary Tables}

\section{Table S1}

Multiple Group Regression Results of How Respondent Tried to Change Distressed Spouse's Perspective Predicted by Covariates and How Personally and Relationally Stressful Spouse's Distress Was

\begin{tabular}{|c|c|c|c|c|}
\hline & $\begin{array}{l}\text { Men with } \\
\text { Men }\end{array}$ & $\begin{array}{l}\text { Men with } \\
\text { Women }\end{array}$ & $\begin{array}{l}\text { Women with } \\
\text { Men }\end{array}$ & $\begin{array}{l}\text { Women with } \\
\text { Women }\end{array}$ \\
\hline & $(n=212)$ & $(n=115)$ & $(\mathrm{n}=115)$ & $(\mathrm{n}=314)$ \\
\hline $\begin{array}{l}\text { DV: Respondent tried to change distressed spouse's } \\
\text { perspective }\end{array}$ & $\mathrm{b}(\mathrm{SE})$ & $\mathrm{b}(\mathrm{SE})$ & $\mathrm{b}(\mathrm{SE})$ & $\mathrm{b}(\mathrm{SE})$ \\
\hline College degree or more & $0.09(0.09)$ & $-0.04(0.14)$ & $-0.07(0.15)$ & $-0.04(0.09)$ \\
\hline Any children in household & $-0.11(0.12)$ & $-0.05(0.15)$ & $-0.04(0.15)$ & $-0.15(0.07)$ \\
\hline Working full-time & $0.03(0.09)$ & $0.00(0.16)$ & $-0.06(0.13)$ & $0.02(0.07)$ \\
\hline Distress event currently ongoing & $-0.03(0.10)$ & $0.06(0.13)$ & $0.21(0.14)$ & $0.01(0.07)$ \\
\hline Time since distress event occurred & $0.01(0.04)$ & $-0.01(0.06)$ & $-0.04(0.06)$ & $-0.02(0.03)$ \\
\hline Relationship duration (years lived together) & $-0.01(0.01)$ & $-0.01(0.01)$ & $-0.01(0.01)$ & $-0.01(0.01)$ \\
\hline Relationship quality & $0.07(0.05)$ & $-0.01(0.06)$ & $0.05(0.06)$ & $0.20 * *(0.04)$ \\
\hline Age & $0.01(0.01)$ & $0.00(0.01)$ & $-0.01(0.01)$ & $0.00(0.01)$ \\
\hline Own depressive symptoms & $0.00(0.01)$ & $-0.01(0.01)$ & $-0.01(0.01)$ & $0.01(0.01)$ \\
\hline Spouse's depressive symptoms & $0.01(0.01)$ & $0.00(0.01)$ & $0.01(0.01)$ & $-0.01(0.01)$ \\
\hline How stressful spouse's distress was personally & $0.05(0.05)$ & $-0.01(0.09)$ & $0.09(0.08)$ & $0.04(0.04)$ \\
\hline How stressful spouse's distress was relationally & $-0.03(0.04)$ & $0.04(0.07)$ & $-0.08(0.06)$ & $-0.02(0.03)$ \\
\hline Constant & $2.78(0.51)$ & $3.81(0.66)$ & $3.81(0.66)$ & $2.56(0.44)$ \\
\hline
\end{tabular}

$* p<0.05 ; * *<0.01$. 


\section{Table S2}

Multiple Group Regression Results of How Respondent Gave Distressed Spouse Time and Space Predicted by Covariates and How

Personally and Relationally Stressful Spouse's Distress Was

\begin{tabular}{lcccc}
\hline & $\begin{array}{c}\text { Men with } \\
\text { Men }\end{array}$ & $\begin{array}{c}\text { Men with } \\
\text { Women }\end{array}$ & $\begin{array}{c}\text { Women with } \\
\text { Men }\end{array}$ & $\begin{array}{c}\text { Women with } \\
\text { Women }\end{array}$ \\
\hline & $(\mathrm{n}=212)$ & $(\mathrm{n}=115)$ & $(\mathrm{n}=115)$ & $(\mathrm{n}=314)$ \\
\hline DV: Respondent gave distressed spouse time and & $\mathrm{b}(\mathrm{SE})$ & $\mathrm{b}(\mathrm{SE})$ & $\mathrm{b}(\mathrm{SE})$ & $\mathrm{b}(\mathrm{SE})$ \\
space & $0.01(0.10)$ & $0.12(0.12)$ & $-0.21(0.13)$ & $0.10(0.09)$ \\
College degree or more & $-0.18(0.12)$ & $-0.11(0.13)$ & $-0.13(0.13)$ & $0.15(0.08)$ \\
Any children in household & $0.04(0.10)$ & $-0.03(0.14)$ & $-0.02(0.11)$ & $-0.07(0.08)$ \\
Working full-time & $0.08(0.10)$ & $0.29 *(0.11)$ & $0.06(0.13)$ & $-0.02(0.07)$ \\
Distress event currently ongoing & $0.06(0.04)$ & $0.07(0.05)$ & $-0.01(0.05)$ & $-0.02(0.03)$ \\
Time since distress event occurred & $0.01(0.01)$ & $0.00(0.01)$ & $0.00(0.01)$ & $0.00(0.01)$ \\
Relationship duration (years lived together) & $0.04(0.05)$ & $-0.09(0.05)$ & $0.02(0.05)$ & $0.10(0.04)$ \\
Relationship quality & $-0.01(0.01)$ & $0.00(0.01)$ & $0.00(0.01)$ & $0.01(0.01)$ \\
Age & $0.00(0.01)$ & $-0.01(0.01)$ & $-0.02(0.01)$ & $0.01(0.01)$ \\
Own depressive symptoms & $0.01(0.01)$ & $0.01(0.01)$ & $-0.01(0.01)$ & $0.01(0.01)$ \\
Spouse's depressive symptoms & $0.06(0.05)$ & $0.06(0.08)$ & $0.22^{* *}(0.07)$ & $0.00(0.04)$ \\
How stressful spouse's distress was personally & $-0.06(0.04)$ & $-0.06(0.06)$ & $-0.09(0.06)$ & $-0.03(0.04)$ \\
How stressful spouse's distress was relationally & $3.00(0.54)$ & $3.46(0.60)$ & $3.46(0.60)$ & $2.30(0.46)$ \\
Constant & & &
\end{tabular}

$* p<0.05 ; * *<0.01$. 


\section{Table S3}

Multiple Group Regression Results of How Respondent Took Care of Distressed Spouse's Tasks Predicted by Covariates and How

Personally and Relationally Stressful Spouse's Distress Was

\begin{tabular}{|c|c|c|c|c|}
\hline & $\begin{array}{l}\text { Men with } \\
\text { Men }\end{array}$ & $\begin{array}{l}\text { Men with } \\
\text { Women }\end{array}$ & $\begin{array}{l}\text { Women with } \\
\text { Men }\end{array}$ & $\begin{array}{l}\text { Women with } \\
\text { Women }\end{array}$ \\
\hline & $(n=212)$ & $(n=115)$ & $(\mathrm{n}=115)$ & $(n=314)$ \\
\hline $\begin{array}{l}\text { DV: Respondent took care of distressed spouse's } \\
\text { normal tasks }\end{array}$ & $\mathrm{b}(\mathrm{SE})$ & $\mathrm{b}(\mathrm{SE})$ & $\mathrm{b}(\mathrm{SE})$ & $\mathrm{b}(\mathrm{SE})$ \\
\hline College degree or more & $0.26(0.15)$ & $-0.07(0.18)$ & $0.25(0.20)$ & $-0.07(0.14)$ \\
\hline Any children in household & $-0.22(0.19)$ & $0.11(0.20)$ & $-0.20(0.20)$ & $0.07(0.12)$ \\
\hline Working full-time & $-0.10(0.15)$ & $0.06(0.22)$ & $-0.24(0.16)$ & $0.04(0.11)$ \\
\hline Distress event currently ongoing & $0.03(0.16)$ & $0.10(0.17)$ & $0.01(0.19)$ & $0.10(0.10)$ \\
\hline Time since distress event occurred & $-0.12(0.06)$ & $0.12(0.08)$ & $0.09(0.08)$ & $0.01(0.04)$ \\
\hline Relationship duration (years lived together) & $0.01(0.01)$ & $0.01(0.01)$ & $0.01(0.01)$ & $0.01(0.01)$ \\
\hline Relationship quality & $0.07(0.08)$ & $-0.06(0.08)$ & $0.08(0.08)$ & $-0.05(0.06)$ \\
\hline Age & $-0.01(0.01)$ & $-0.01(0.01)$ & $-0.04(0.02)$ & $-0.02 *(0.01)$ \\
\hline Own depressive symptoms & $0.02(0.01)$ & $0.00(0.02)$ & $0.01(0.02)$ & $0.00(0.01)$ \\
\hline Spouse’s depressive symptoms & $-0.02(0.01)$ & $0.00(0.02)$ & $0.02(0.02)$ & $0.02(0.01)$ \\
\hline How stressful spouse's distress was personally & $0.06(0.07)$ & $0.17(0.12)$ & $0.17(0.11)$ & $0.18 * *(0.06)$ \\
\hline How stressful spouse's distress was relationally & $0.03(0.07)$ & $-0.11(0.09)$ & $0.02(0.09)$ & $-0.14 * *(0.05)$ \\
\hline Constant & $2.76(0.81)$ & $2.79(0.92)$ & $2.79(0.92)$ & $3.46(0.68)$ \\
\hline
\end{tabular}

$* p<0.05 ; * * p<0.01$. 


\section{Table S4}

Multiple Group Regression Results of How Respondent Encouraged Distressed Spouse to Talk Predicted by Covariates and How

Personally and Relationally Stressful Spouse's Distress Was

\begin{tabular}{|c|c|c|c|c|}
\hline & $\begin{array}{l}\text { Men with } \\
\text { Men }\end{array}$ & $\begin{array}{l}\text { Men with } \\
\text { Women }\end{array}$ & $\begin{array}{l}\text { Women with } \\
\text { Men }\end{array}$ & $\begin{array}{l}\text { Women with } \\
\text { Women }\end{array}$ \\
\hline & $(n=212)$ & $(n=115)$ & $(\mathrm{n}=115)$ & $(n=314)$ \\
\hline $\begin{array}{l}\text { DV: Respondent encouraged distressed spouse to } \\
\text { talk }\end{array}$ & $\mathrm{b}(\mathrm{SE})$ & $\mathrm{b}(\mathrm{SE})$ & $\mathrm{b}(\mathrm{SE})$ & $\mathrm{b}(\mathrm{SE})$ \\
\hline College degree or more & $0.20(0.12)$ & $0.19(0.15)$ & $0.07(0.17)$ & $0.15(0.10)$ \\
\hline Any children in household & $0.01(0.16)$ & $-0.13(0.17)$ & $0.13(0.16)$ & $-0.07(0.09)$ \\
\hline Working full-time & $0.11(0.12)$ & $0.02(0.18)$ & $0.15(0.14)$ & $0.03(0.08)$ \\
\hline Distress event currently ongoing & $-0.05(0.12)$ & $-0.15(0.15)$ & $0.13(0.16)$ & $0.08(0.07)$ \\
\hline Time since distress event occurred & $-0.02(0.05)$ & $0.06(0.06)$ & $-0.01(0.06)$ & $0.04(0.03)$ \\
\hline Relationship duration (years lived together) & $0.00(0.01)$ & $0.00(0.01)$ & $-0.01(0.01)$ & $0.00(0.01)$ \\
\hline Relationship quality & $0.09(0.07)$ & $0.08(0.07)$ & $0.03(0.07)$ & $0.16 * *(0.05)$ \\
\hline Age & $0.00(0.01)$ & $-0.01(0.01)$ & $0.00(0.01)$ & $-0.01(0.01)$ \\
\hline Own depressive symptoms & $0.02(0.01)$ & $0.01(0.01)$ & $0.02(0.01)$ & $0.00(0.01)$ \\
\hline Spouse's depressive symptoms & $-0.02(0.01)$ & $0.02(0.01)$ & $-0.01(0.01)$ & $0.01(0.01)$ \\
\hline How stressful spouse's distress was personally & $0.03(0.06)$ & $0.05(0.10)$ & $0.27 * *(0.09)$ & $0.05(0.04)$ \\
\hline How stressful spouse's distress was relationally & $-0.02(0.05)$ & $0.00(0.08)$ & $-0.12(0.07)$ & $-0.07 *(0.04)$ \\
\hline Constant & $2.85(0.66)$ & $2.53(0.75)$ & $2.53(0.75)$ & $2.59(0.50)$ \\
\hline
\end{tabular}

$* p<0.05 ; * * p<0.01$. 